Infrastructure Asset Management

Volume 2 Issue 1

Customer perceptions of road infrastructure surface conditions

Blom, De Marco and Guthrie
Infrastructure Asset Management, 2015, 2(1), 23-38

http://dx.doi.org/10.1680/iasma.15.00001

Paper 1500001

Received 27/01/2015; accepted 19/03/2015

Keywords: management/roads \& highways/social impact

ICE Publishing: All rights reserved
,

\title{
Customer perceptions of road infrastructure surface conditions
}

Carron M. Blom MSc (Hons), FIPENZ, MRMLA, MRSNZ, MAMINZ PhD Candidate, University of Cambridge, Cambridge, UK

Luca De Marco MSc, CEng, MICE

Principal Asset Manager, New Zealand Transport Agency, Wellington, New Zealand
Peter M. Guthrie OBE, FREng, FICE

Director of the Centre for Sustainable Development, Department of Engineering, University of Cambridge, Cambridge, UK

Performance is a key tenet of infrastructure management. This paper looks at a measure of service level in infrastructure, namely, road smoothness. Conventionally, studies of this type have focused on the technical measures themselves. This paper presents the results of the first stage of a New Zealand-based case study that, by contrast, explored the engineering processes through the lens of the outcomes they sought to achieve; in this instance, customer comfort. The paper asserts that if performance is to be determined by outcomes, then a holistic approach is needed, including a revised definition of technical performance.

\section{Introduction}

During the 1980s, the concept of 'new public management' emerged, and with it a greater emphasis on businesslike performance and stakeholder collaboration (Dunleavy and Hood, 1994; Hendriks and Tops, 1999, 2003; Hood, 1991; Lowndes, 1997). This has latterly converged in the realm of public infrastructure with the emergence of performance or service-led infrastructure management. This approach is especially evident in the domain of asset management wherein level of service, or performance, is a key tenet (e.g. New Zealand Asset Management Support (NAMS), 2007). Consequently, public infrastructure organisations, such as local government, are often required to articulate service-level objectives and to report regularly on performance (e.g. Department of Internal Affairs, 2013).

Among its other functions, the New Zealand Transport Agency (NZTA) manages New Zealand's state highway network, including maintenance, improvements and operations activities. It has recently articulated a series of long-term (20-year) goals that see a renewed focus on customer service and outcomes (New Zealand Transport Agency, 2014). The aspirations cascade into performance expectations, organisational key result areas and performance indicators. In particular, these recognise that there is a need to better understand its customers' attitudes, needs and behaviours.

This paper summarises the first part of a case study of customer perceptions of the surface of road infrastructure. It has a direct relationship with NZTA's comfort service key result area, which is measured by road smoothness. One of the aims of the study was to assist the integration of customer feedback within decision making and prioritisation processes so that the services provided could be better aligned to customer needs. Accordingly, this also underpinned another strategic objective: making better use of existing assets (Ministry of Transport, 2013; New Zealand Government, 2011) (see also Dobbs et al., 2013). The study provides part of the background for a wider consideration of the effect of engineering decision making upon infrastructure outcomes.

\section{Roughness indicators}

The NZTA has adopted road smoothness as an indicator of customer comfort, technical conditions (e.g. surface and/or subsurface condition; Brown et al., 2010), and road user costs. ASTM E867 defines road smoothness as 'the deviations of the surface from a true planar surface with characteristic dimensions that affect vehicle dynamics, ride quality, dynamic loads and drainage' (cited in Brown et al., 2010; Solhmirzaei et al., 2012; Wilson et al., 2013). Many roads are of course not planar, but the deviations in the road surface are of interest to this study.

The International Roughness Index (IRI) and the Smooth Travel Exposure (STE) are both measures of road smoothness that have been widely used internationally for some time (e.g. Geiger et al., 2005; Haas et al., 2009; Henning et al., 2013; Noxon Associates Limited, 2011; Wilson et al., 2013). Both measures purport to measure road user travel comfort and focus on how effectively changes in the longitudinal road profile are absorbed by vehicle suspension and then perceived by the user (Brown et al., 2010; Henning et al., 2013).

The NZTA currently measures the longitudinal profile of the highway network using lasers located over each wheel path, in conjunction with accelerometers fitted on the transverse beam of the survey vehicle. The IRI is then calculated from this longitudinal profile and reported every $20 \mathrm{~m}$ (New Zealand Transport Agency, 2009).

Despite its prevalence, the use of the IRI has been questioned (e.g. Brown et al., 2010). One of the concerns with the indicator is the adequate assessment of roughness from a human health and 
comfort perspective (e.g. Kropáč and Múčka, 2005; Lenngren and Granlund, 2002). By contrast, Haas et al. (2009) argue

But the public mainly notices the discomfort. Policy-makers can easily misunderstand a presentation of IRI as mainly a measure of ride comfort, and under-value the economic implications unless the transportation values of travel time and user cost are also presented. Thus, even though the IRI is objectivity measured, its misuse can cause its objectivity to be lost.

A review of literature and several focused industry interviews suggests that, from the perspective of customer-led infrastructure strategies, there are issues with the current indicators and approach

- The IRI and STE are vehicular measures and so do not necessarily provide a suitable index for other modes (e.g. cyclists, pedestrians), or customer (user) variability (e.g. children, elderly, mobility impaired).

- There is an inherent assumption that road smoothness is indeed a good indicator of comfort from the customers' perspective.

- There is an apparent disconnect with how road smoothness is related to comfort and then actually used by practitioners or decision makers to change customer outcomes.

The issues do not, however, mean that the indicators are not appropriate for the other technical uses to which they are put (Henning et al., 2013; New Zealand Transport Agency, 2000, 2013). For example, road smoothness, as an indicator of road condition, is now a mandatory reporting requirement for local government (Department of Internal Affairs, 2013). Consequently, this paper does not consider the wider technical merit of the indicators for issues such as road user costs, road condition or noise. Rather, the identified issues underline the need for this research, which considers the relevance of the indices from the customers' perspective, since this is how the performance strategies have been expressed.

\section{Customer satisfaction indicators}

Further review of industry and academic literature indicated that the use of roughness factors is often augmented by general customer satisfaction surveys. Such surveys frequently include road smoothness as one of the factors that customers are often asked to prioritise or rank. For example, the NZTA contributes to the biennial user satisfaction survey undertaken by AustRoads (2011). However, surveys such as this do not enable direct comparison between IRI and customer feedback (see also Neely and Bourne, 2000). Furthermore, user satisfaction is multidimensional, does not solely depend on physical attributes and does not necessarily accord with technical/engineering conditions (Department of Transport of Wisconsin, Iowa and Minnesota cited in Ramdas et al., 2007).

This was a recurring theme and was similarly the case with annual local government surveys (e.g. Key Research, 2013; Versus Research, 2013), as well as studies undertaken by, for example,
Bonsall et al. (2005); Department for Transport (UK) (2012); Eboli and Mazzulla (2009); the Government of Karnataka (2004); Jinxing \& Wenquan in Brebbia (2014); and Ramdas et al. (2007). This was acknowledged by Bonsall et al. (2005), who observed that few studies considered customers' beliefs. Indeed, there appear to be few related studies that consider the customer from the customers' perspective at all.

\section{Methodology}

The subject case study, which describes the outcomes from a series of customer focus groups, is part of a wider research programme (Figure 1). Focus group locations were selected to reflect the national organisational accountabilities of the NZTA. Locations were therefore sought in both the North and South Islands of New Zealand, and within rural and urban centres as follows

- Napier

- Christchurch

- Dunedin.

As Christchurch's infrastructure is still being redeveloped postearthquake, there was the possibility that the discussion would centre on related issues; this, however, did not transpire.

Some time was spent considering who the NZTA's customers were, so that appropriate groups could be established. Given the aims of this stage, it was decided to target user or advocacy groups rather than trying to arrange a sample of random yet representative individuals. While this arguably brings an inherent bias in the form of mode or user-specific positions, this was considered appropriate in this instance for the following reasons

- The purpose of the process was to elucidate the language specific to, and the needs of, each mode and user group.

- The information was to be used to shape a more extensive appraisal of individual need in the form of a questionnaire proposed as a later stage (Figure 1).

Any bias was also tempered by the structuring of the focus group sessions (discussed below), which facilitated a shared understanding across mode and user groups by starting with the higher-level concepts (discussed further below; also, see Figure 1).

A range of potential customer groups were identified and provided to the NZTA's Journey Managers, who then sent out invitations based on local knowledge and availability. The invitations called for customer participants that were 'interested and available' on a voluntary basis. Potential customer groups identified included the following

- Car clubs (e.g. Automobile Association)

- Advocacy for the elderly (e.g. Grey Power/Age Concern)

- Disability advocacy (e.g. Be Accessible, Blind Foundation)

- Cycling groups (e.g. SPOKES) 


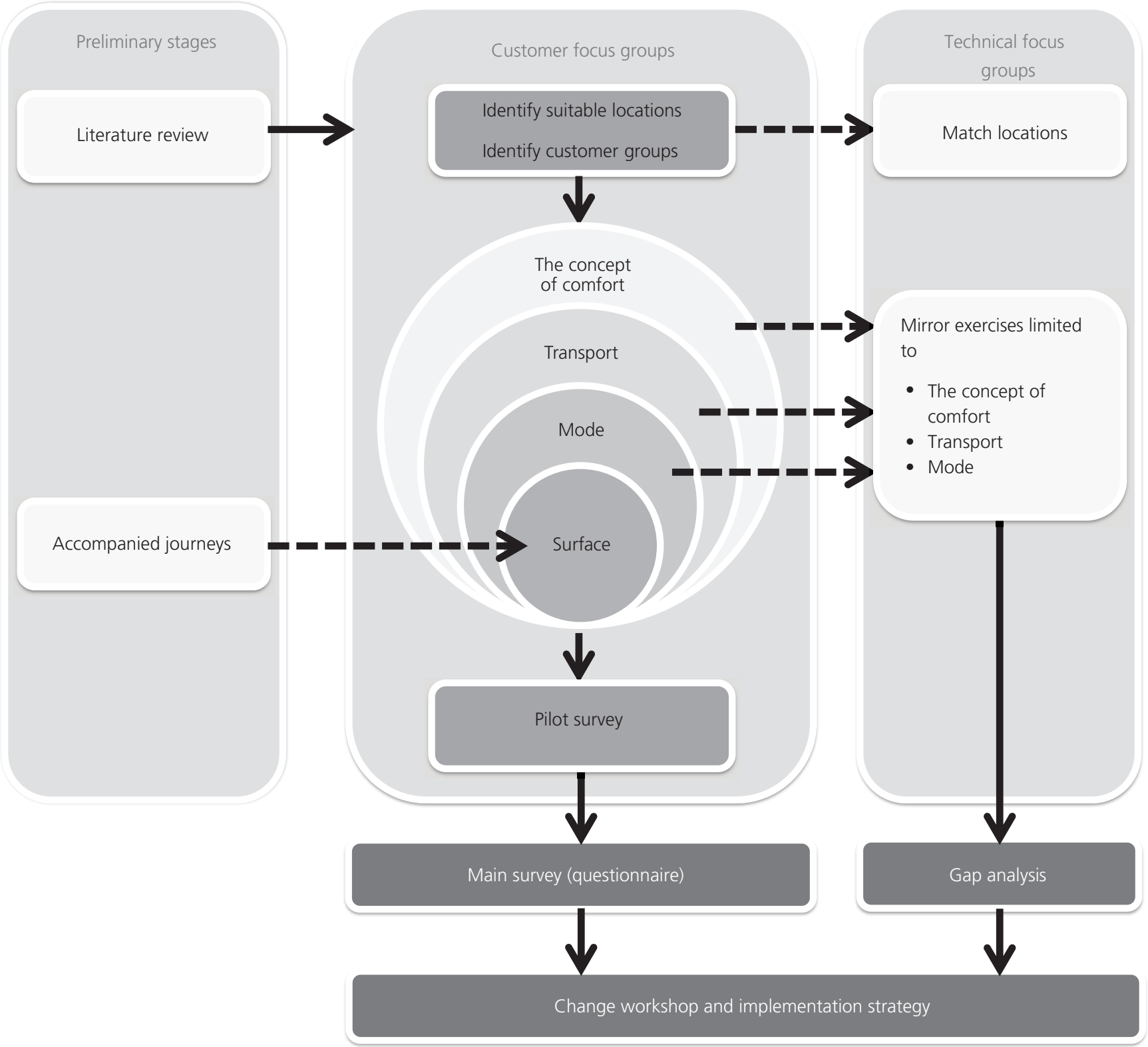

Figure 1. Methodology

- Universities/schools

- Those living beside roads and paths

- Other local interest groups (e.g. Marae)

- Freight related advocacy (e.g. Freight Association)

- Bus-related advocacy (e.g. Bus and Coach Association)

- Rural sector (e.g. Federated Farmers)

- Children's advocates (e.g. Plunket)

- Emergency services

- Motorcyclists

A total of 28 adult customers participated across the country (12 in Napier, 10 in Christchurch and 6 in Dunedin). This provided a diverse array of mode and user groups as summarised in Table 1.
In some instances, an NZTA staff member was nominated by a user group, or helped to make up numbers to represent an underrepresented customer group, particularly in the smaller centres. This was closely managed. No more than two NZTA staff participated in each of the customer sessions. In such instances, the staff were advised that they were there as a customer and to avoid technical discussions or wearing an 'NZTA hat'. Where conversations drifted into such matters, these were addressed within the workshop and participants guided back to their role as a customer or user.

The focus groups were facilitated by the principal author of this paper and were part of both a consultancy appointment and 


\begin{tabular}{l}
\hline Customer group \\
Freight \\
Bus \\
Emergency services \\
Taxi \\
Car \\
Motorcyclist/moped \\
Parents (pushchairs, children) \\
Disabilities (e.g. mobility, sight impaired, wheel chair \\
user) \\
Elderly (including mobility scooter users) \\
Horse riders \\
Cyclists \\
Pedestrians (including walking school bus) \\
Skateboarders/push scooters \\
Farm vehicles \\
Touristfirst-time user \\
Residents interest group (customers living beside the \\
Tosset)
\end{tabular}

auestionnaire not piloted in Christchurch.

= Mode or user group advocacy representation (does not indicate participant gender).

- = Mode use from pilot questionnaire.

Table 1. Summary of focus group participation

academic research programme. The initial brief was to follow the methods used by a UK study (Ramdas et al., 2007). However, this was modified from the outset by the lead author to incorporate focus groups to establish a preliminary view of the issues and to shape the subsequent questionnaire. In the end, other than sharing the methodological use of a questionnaire, only the accompanied journey component of the UK study remained (and is not addressed within this paper). While the accompanied journey work had merit from a consultancy perspective, it has not been integrated within the wider research programme (except to provide photographic examples of technical defects). This important philosophical and methodological departure enabled the work to be developed as action research (Stokols, 2006).

The core workshop (covered by this paper) lasted $2 \cdot 5 \mathrm{~h}$ at each location. While the focus groups provide valuable insights in their own right, the underlying purpose was to inform and shape a proposed questionnaire. Additional time was spent at both Napier and Dunedin to pilot the first draft of the questionnaire (see Figure 1). The questionnaire was also subsequently modified to reflect the issues raised in all three focus groups. That process and the results of the survey are to be addressed within a separate paper. 
Infrastructure Asset Management

Volume 2 Issue 1
Customer perceptions of road

infrastructure surface conditions

Blom, De Marco and Guthrie
Although accountability for footpaths along New Zealand's highway network has been delegated to the relevant local authority (albeit partially funded through the NZTA), pedestrians and other users may still cross the carriageway. It was also suspected that customers may not distinguish between or discern administrative boundaries. Consequently, this case study considered the wider road corridor (i.e. both roads and footpaths). Typical road crosssections are given within Figure 2.

As few studies appear to have asked their customers what comfort means to them, the first part of the focus group session started with the broad concept of comfort and explored what this meant to participants, canvassing the language used and the breadth of the factors identified. A series of cascading questions followed (Figure 3), which explored the concept of comfort as it related to transport generally and then to a range of land transport-based modes and user groups.

This essentially inverted conventional approaches to this topic and was subsequently found to be an effective means of enabling engagement, especially where modal or user tensions gave rise to competing needs. The different approach to each question (described below), along with approaching the matter of comfort from a range of different angles enabled the possibility of triangulation both within
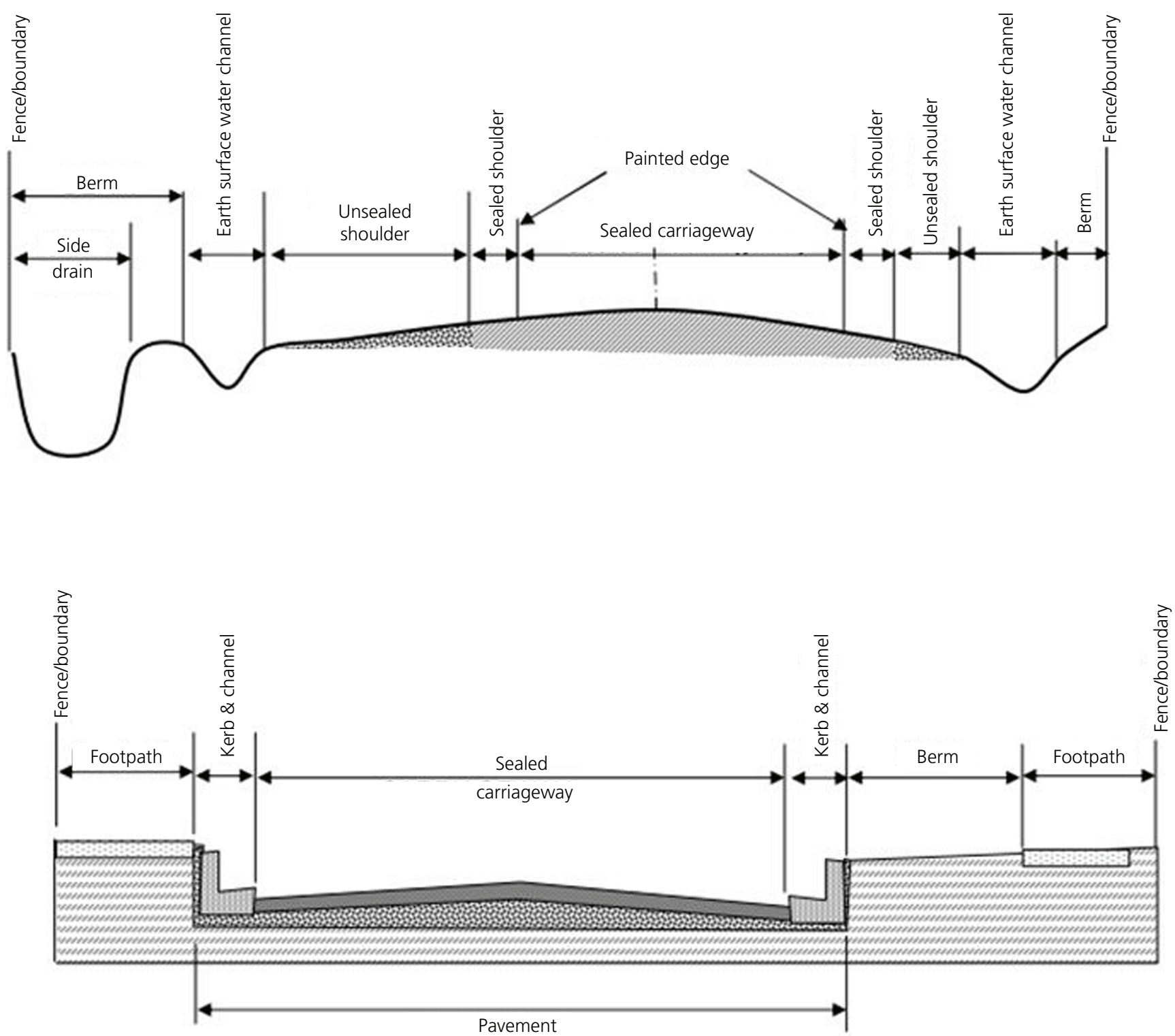

Figure 2. Typical cross-sections for rural (top) and urban (bottom) roads. Source: Transfund New Zealand (1997, p. 7). Note: In

New Zealand, a 'sealed road' is a generic term and so does not necessarily reflect the materials used to construct the road surface 


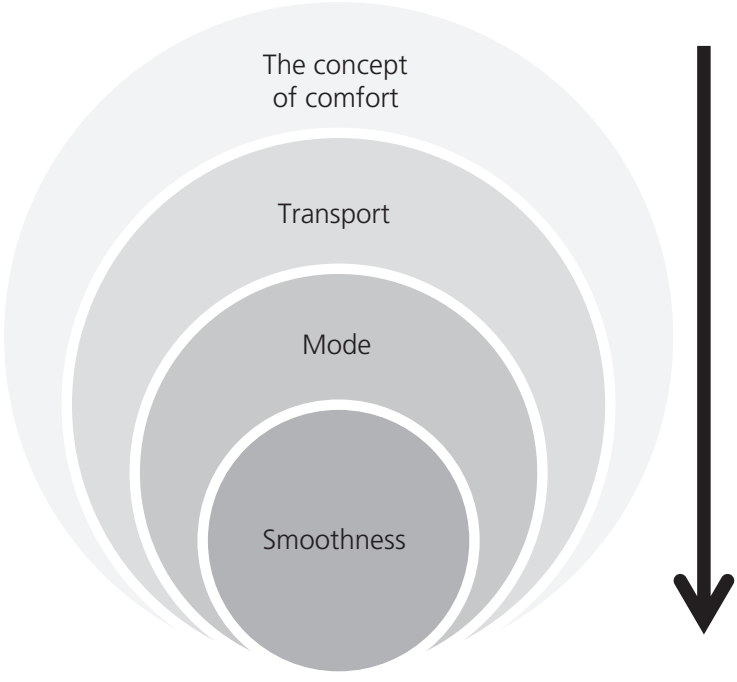

Q1: What does comfort mean to you?

Q2: What does comfort mean to you in relation to transport or travel generally?

Q3: What does comfort mean to each of these mode/user groups?

Q4: How do pavement issues affect your comfort?

Figure 3. Exploring comfort

each workshop and between the focus groups themselves (Eisenhardt, 1989; Krefting, 1991). The approach recognises that the notion of comfort as it relates to road infrastructure may be a latent variable, which needs to be explored by obtaining the participants' sense of what it is or by exploring other attributes which together make up comfort (Eboli and Mazzulla, 2009; Parasuraman et al., 1985, 1994).

The first two focus group questions (Figure 3) were discussed in pairs to identify 'keywords' or 'factors'. These were then pooled and grouped by all participants into key 'themes' and those themes discussed. Common or varying language and terminologies were explored. These were subsequently analysed across all three of the focus groups to ascertain whether there were any commonalities (termed 'notions of comfort').

While general concepts and phrases may have been expressed for the notion of comfort generally, participants were asked to be more specific in relation to defining comfort in transport and by mode. For example, 'safety' was a common overarching theme, and as the focus narrowed, participants were asked to consider what safety factors affected comfort at each, more refined, level.

Prior to advancing to the third question (Figure 3), participants were asked to briefly share their understanding of what comprised the road corridor. This was to prime participants to subsequently focus down on road-related comfort issues and also provided a chance to reflect on how the customer understood any differences between highway and local road accountabilities.

The subsequent mode/user discussion involved small group work. Participants were invited to view and add to the factors identified by other groups and then participants were invited to identify the most important factors affecting comfort for them (irrespective of mode).
Finally, participants were asked to comment on a range of technical footpath and road pavement defects. Some 160 photographs were prepared based largely on the preceding accompanied journey surveys (Figure 1). Additional photographs were added to augment the range of issues presented, and there was an overall balance of road and footpath-related issues.

\section{Results}

The notion of comfort

Participants were first asked to identify keywords and then from these, the emergent themes describing comfort as a general concept. Key words or synonyms sometimes appeared across themes. However, while noting the similarities, the groups made the point that the groupings or themes expressed different aspects of comfort as a general concept.

Themes from each of the workshops were later subjected to a further level of analysis, from which eight 'notions of comfort' were derived from across the three focus groups (Table 2). For example, health, positive emotions, company and food were uniformly grouped together (I have a sense of wellbeing and community) and were grouped separately from the themes around relaxation and peace (I have peace of mind and am at ease). To cross check this synthesis, overarching word frequency analysis (irrespective of the underlying themes) showed that key words aligned with the majority of these notions. Limited synonym clustering of less used terms gave full alignment.

Comfort and discomfort also emerged as distinct notions; comfort is 'more noticeable when it is absent'. Pain was one example given by workshop participants. Pain can cause discomfort, but its absence does not result in comfort. Road smoothness was later identified 


\begin{tabular}{|c|c|}
\hline Notions of comfort & $\begin{array}{l}\text { Keywords within customer-generated themes } \\
\text { (selected examples) }\end{array}$ \\
\hline I have freedom and choice & $\begin{array}{l}\text { - Choice (free to choose) } \\
\text { - } \text { Freedom } \\
\text { - Being able to do the things you want to do }\end{array}$ \\
\hline Life is hassle free & $\begin{array}{l}\text { - Convenience } \\
\text { - Easy }\end{array}$ \\
\hline I feel safe & $\begin{array}{l}\text { - Safe } \\
\text { - Security } \\
\text { - No fear }\end{array}$ \\
\hline I have confidence and certainty & $\begin{array}{l}\text { - Familiarity } \\
\text { - Confident } \\
\text { - Certainty } \\
\text { - Ability to respond to the situation }\end{array}$ \\
\hline I have a sense of well-being and community & $\begin{array}{l}\text { - Well-fed and watered } \\
\text { - Inclusive } \\
\text { - Friends, family } \\
\text { - Happy, contented }\end{array}$ \\
\hline I have a good personal environment & $\begin{array}{l}\text { - Soft/hard, warm/cold (depending on say back) } \\
\text { - No pain/discomfort } \\
\text { - Controlled noise/sounds } \\
\text { - Smells }\end{array}$ \\
\hline I have a sense of place & $\begin{array}{l}\text { - Visually appealing } \\
\text { - Surroundings (nice place, view, environment) } \\
\text { - Awareness } \\
\text { - Environment in }\end{array}$ \\
\hline I have peace of mind and am at ease & $\begin{array}{l}\text { - } \text { Relaxed } \\
\text { - Stress/anxiety free } \\
\text { - } \quad \text { No pressure }\end{array}$ \\
\hline
\end{tabular}

Table 2. Notions of comfort

as another such example; a poor road surface may make someone uncomfortable, however, a smooth road does not necessarily make a person comfortable.

The customers themselves observed that comfort was described both emotionally and physically, and that it had a personal dimension or scale: 'Some people don't mind and are comfortable learning [going outside their personal comfort zone] whereas others want things under control'. A range of other influencing factors were also identified, such as whether a person was relaxed, stressed, safe, and physically comfortable or in a good environment, highlighting the interconnectedness of the eight comfort factors listed above. Comfort was associated with 'luxury and pampering, something special'; a positive attribute, again distinguishing it from discomfort. Companionship was also identified as being particularly important: 'Even if you go to an unfamiliar place it helps to have someone with you. Shared experiences are important'.

\section{Comfort in transportation generally}

Not surprisingly, the factors (key words) identified for comfort in transportation became more detailed and specific than those expressed for comfort in general. For example, the factors contributing to a customer defined theme around safety shifted from the generic 'safe', 'non-threatening environment', and 'security' (comfort generally) to 'condition of vehicle', 'appropriate speeds', and 'reduced road side hazards' (comfort in transportation generally). Of the themes that emerged from this exercise, knowledge and information, consistency and control, behaviour (road respect, manners and intimidation), safety, surfaces and overall design, and timeliness were identified as being particularly important.

Although there was some overlapping of keywords across customerdefined themes, analysis showed that these broadly aligned with the same eight high-level notions of comfort (see Table 2). This provided a degree of verification by testing the emergent notions of comfort at a different scale (Heath and Cowley, 2004). The customers did, however, identify an additional theme at this scale, which related to cost and value. Further exploration of this aspect revealed that comfort was important but that this was conditional on the cost to the customer.

One of the key messages to emerge from the customers from this exercise is related to the aspects of timeliness, consistency and 
control and demonstrates the importance of looking beneath terms that might be construed differently in a technical context. Customers in each of the focus groups made the point that most people at some stage in their lives will need to change modes, or become a pedestrian or mobility device user; whether as a child in a pram, or through ageing, illness, or accident. Consistency in the look and feel of roads and paths, and the ability to have control over one's life were seen as vital to comfort in this context. Timeliness was flagged not because of congestion delays but because constraints such as road works might cause someone with a mobility or disability device to be house bound and isolated for days or even weeks. Timeliness, consistency and control were therefore interwoven with notions of self-expression, freedom and community inclusion, all of which were seen by the customer groups as impacting on the comfort of those who were more vulnerable.

Where engineers are using comfort as a measure and are focusing on ride quality and physical comfort within the road carriageway, they may not be surprised that less tangible issues such as behaviour and timeliness (in the terms described by the customers) may be omitted. Penn in Knight and Ruddock (2008) discusses such a point in relation to the role of architects in the built environment and building design in particular. He talks of retailers creating a 'customer experience' or designers that identify with an 'innovative environment', notions that Penn argues are 'indefinable except as judgements of a building in retrospect'. While a brief or specification cannot define such intangible outcomes, Penn notes that this is what distinguishes architecture as a profession, and why intuition, judgement, and tacit skills learnt within practice are so important. It is argued that engineering is no different but may need to reorient practice back to its societal purpose (Jowitt, 2010). Indeed, an approach that embeds such intangible elements within technical practice is necessary if customer-centric strategies, such as those of the NZTA, are to be meaningfully delivered.

\section{Organisational and administrative boundaries}

When it comes to the road corridor, customers emphatically noted that they weren't aware of, or particularly interested in, the differences in accountability between agencies. Viewed as a single entity comprising roads and footpaths, it was seen not as a corridor, but as a network that helped customers connect with where they wanted to go: 'it is not a railway to get things from A to B', 'corridor is a commercial term and not about the quality of life'; 'network gives you choice'.

An example was cited of two nearby townships which previously had good connectivity. However, with the highway and fast cars, they were seen as now being quite isolated 'unless you have a car' (high speed, narrow, no paths, and facilities all located in one of the towns). In their view, the towns were further apart now than they had been 100 years ago. A change, they felt, that had occurred dramatically in the last few decades: 'New Zealand roads have not kept up and also need to consider all users more'. Footpaths too, in their minds, had not evolved to cope with, say, mobility scooters or to enable parents to walk side by side with pushchairs without impeding other users. Similarly, road 'radii are designed for 30 vehicles... vehicles turn faster - this can be an issue for... people trying to cross at intersections'.

All groups also highlighted the effect on comfort of the different standards between highways and local roads and across local authority or funding boundaries; all of the groups identifying the example of road edge and pull off areas to explain their point. They observed that seal frequently does not extend far beyond fog lines (painted edge; see Figure 2) and is often accompanied by a large level difference even with a sealed shoulder (Figure 2). They saw this as a funding boundary (pavement width) and maintenance or contract boundary (transition between surfaces).

The issues this raised for customers were numerous and ranged from an inability to pull off, reduced manoeuvrability (trucks) and effective lane width (cyclists), risk of overturning, risk of tripping, and the risk of getting stuck or breaking mobility devices. Customers commented that they were uncomfortable with the uncertainty that these factors caused, highlighting a difference between technical acceptance and perceived user comfort. More specifically, while high shoulders with a specified level of rutting would be defined as 'ineffective' from a technical perspective (Transfund New Zealand, 1997; see Figure 4), the very issue identified by the customer focus groups is expressly identified within NZTA technical guidance as being 'adequate' (see Transfund New Zealand, 1997; see Figure 5). This would suggest not only the need to consider a measure for footpaths and road crosssectional profiles (particularly at crossing points and intersections), but also the need to review technical specifications, and embedded processes and procedures to align with strategic objectives.

Customers noted that a holistic approach was required; a solution for one mode can cause problems for another. Citing rumble strips which push trucks out from the edge, they observed that this reduces traffic separation but creates space for cyclists (see also Johnson, undated). Similarly, exposed aggregate footpaths might assist with grip but break canes used by the sight impaired.

In customers' minds, then, transportation comfort was not just limited to the interaction with the physical asset or means of travel. Customers instead expressed a need for a holistic, system view to be adopted as comfort on the asset itself was a subset of comfort in their wider lives.

\section{Transportation mode-specific comfort}

The subsequent mode/user discussion involved small group work; distinguished from the preceding steps by the level of specificity generated. Although most participants drove cars, the results indicate a collective customer view across the focus groups that the mode/user groups with the widest range of issues are those using mobility devices, followed by cyclists (Figure 6). The most frequently identified issue across all the modes was consideration of or by others, followed by road and path surface issues, and road design generally (Figure 7). This reinforces the point made earlier that customers view comfort holistically across all of their mode choices, noting designs for vulnerable users would encompass their needs as a car user, but not the other way around. 


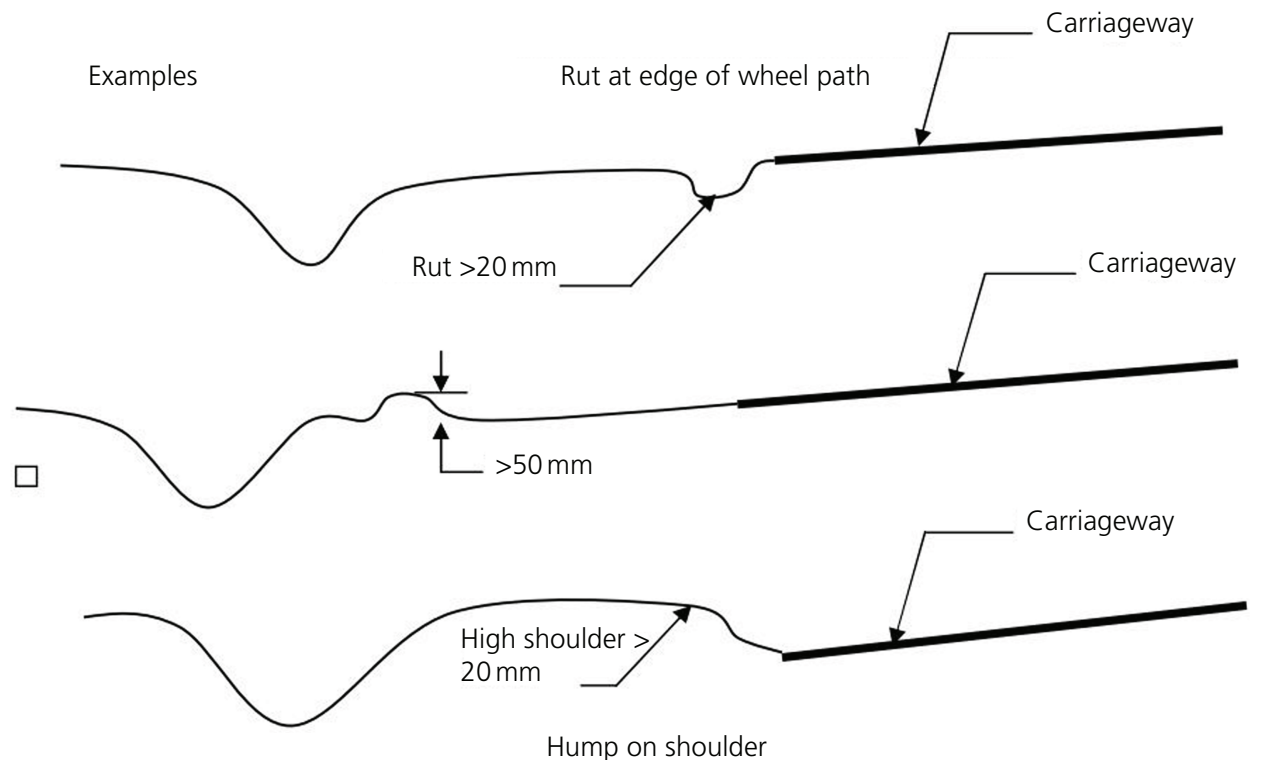

Figure 4. Examples of ineffective and technically inadequate road shoulders. Source: Transfund New Zealand (1997, p. 33)

Low shoulder (should not be rated as inadequate)

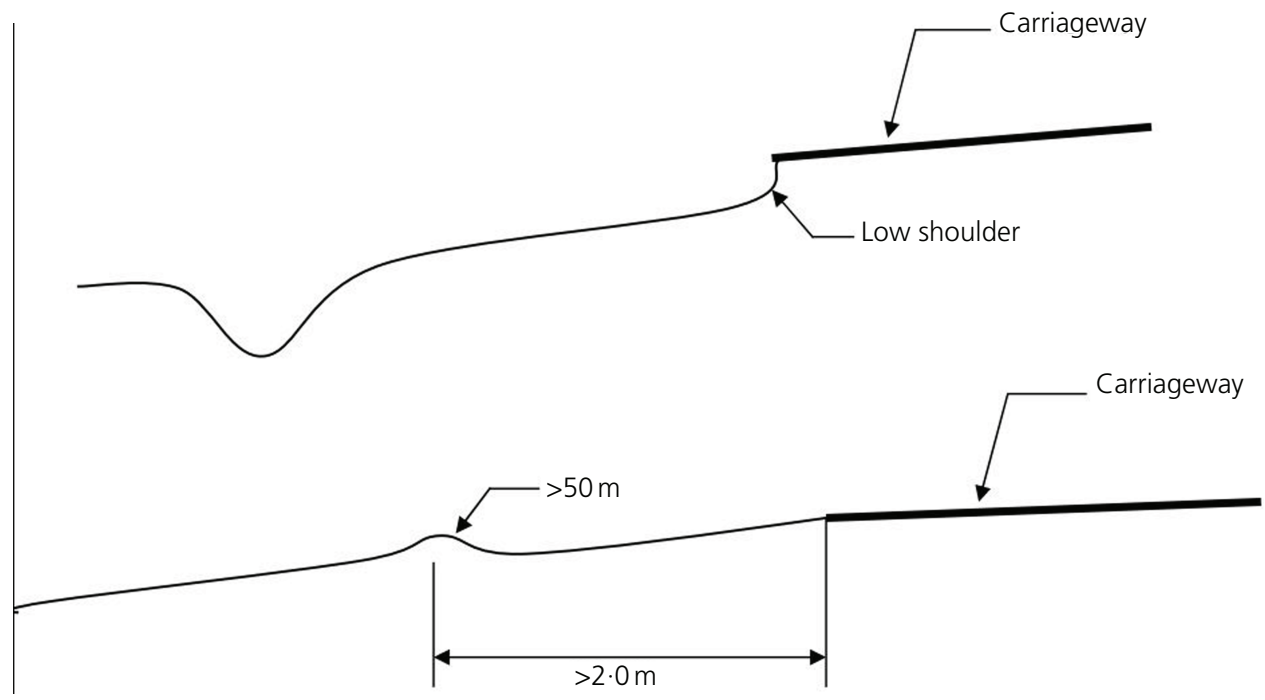

Figure 5. Examples of technically adequate road shoulders.

Source: Transfund New Zealand (1997, p. 34)

Customers were then asked to identify which of all the mode-specific comfort statements/factors were most important to their overall comfort irrespective of the mode or user group for which they were generated. The factors the customer groups saw as critical to comfort are ranked in Table 3. This indicates that while road smoothness is both a frequent and a critical concern, the customers were concerned with a wider range of issues that relate to vulnerable users in the first instance. To address these concerns, pavement smoothness would need to be measured in a way that addressed all user needs, and a range of other comfort indicators may need to be considered.

\section{Pavement-specific issues}

Finally, participants were asked to comment on the comfort effects of a range of technical footpath and road pavement defects. Participants were asked to 'tag' or prioritise these as either intolerable or of high importance, and to briefly note the issue of concern and which mode it affected. Issues and modes were not defined so that participants had a free rein, and notably, this did not constrain customers to matters of pavement smoothness. Participants were, however, asked to focus on issues that related to comfort. 
Infrastructure Asset Management

Volume 2 Issue 1
Customer perceptions of road

infrastructure surface conditions

Blom, De Marco and Guthrie

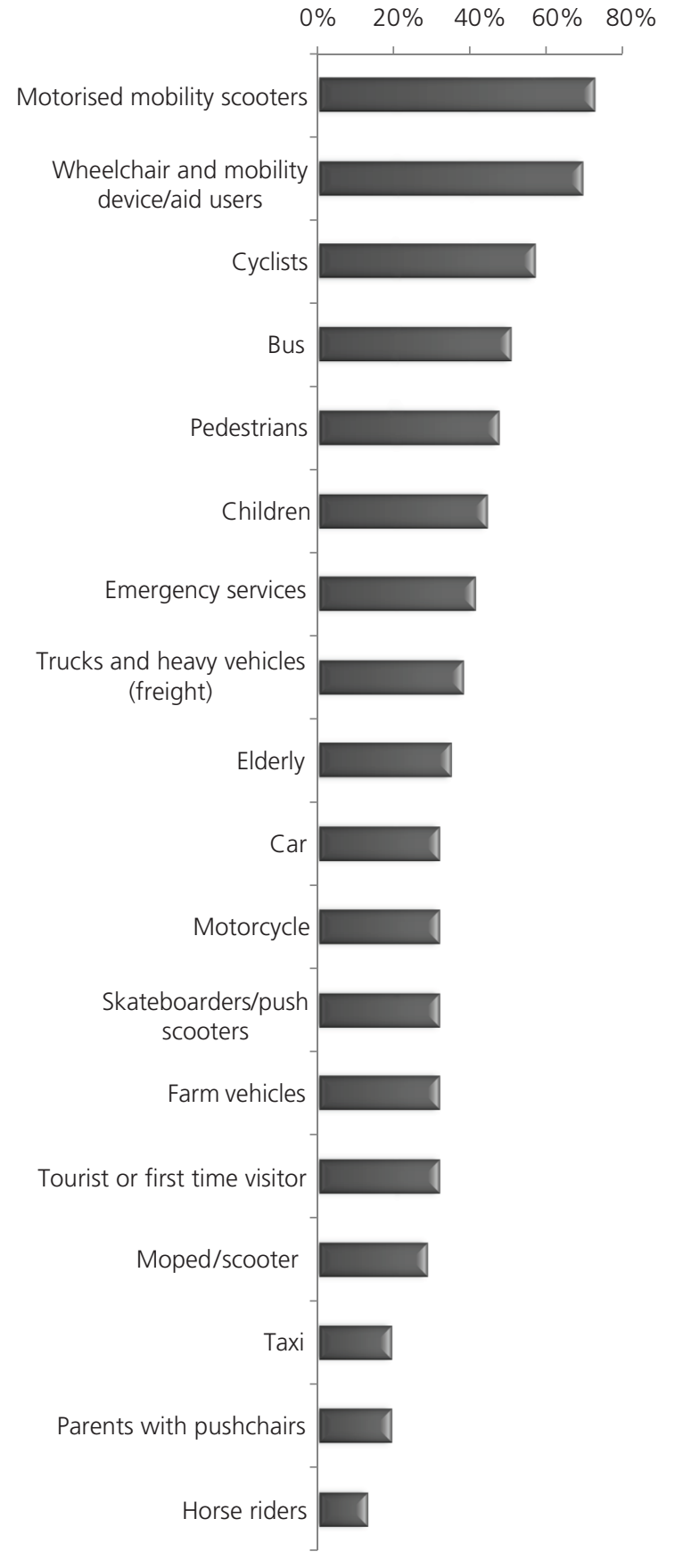

Figure 6. Dominance of comfort factors for each mode or user group. Percentage of the comfort factors (as listed in Figure 7) that were identified as relevant to each mode)

Some $68 \%$ of photos were tagged and of these, $65 \%$ were tagged by more than one focus group, and $28 \%$ by all focus groups. A range of issues were often identified in each photo. Using a presence/ absence indicator, more photos contained an issue for cyclists and pedestrians than any other mode or user group. Frequency analysis of the total number of identified issues was again dominated by those issues specific to cyclists and pedestrians. This was despite the wide range of customer interests represented and the majority of participants using or having access to cars.

An assessment of all keywords used to describe the issues is summarised in Figure 8. This highlights the importance of potential trip hazards to customers, followed closely by the interlinked issues of narrowness/reduced space, and the presence of obstacles. Of note is the pairing of the surface issues with the issue of defects causing customers to swerve (whether into oncoming traffic, or in the case of cyclists, into the live traffic lane). This was also clearly linked in customers' minds at the focus group sessions, with customers noting that it was not so much about smoothness, but where defects were located. The effect of defects in the ride or wheel line not only caused discomfort from bumping, but also from swerving to avoid the issue and creating another comfort issue; that of uncertainty or feeling unsafe from reduced separation caused by the need to swerve into the live traffic lane. Customers indicated that this was also linked to the presence and quality of shoulders (extent of pavement/pavement level changes) discussed earlier.

Figure 9 considers the key words encountered on the top 50 ranked photographs in more detail and compares this with the overall frequency. This encompasses most of the photographs tagged by every group. Given most of the identified issues pertained to cyclists and pedestrians, this analysis indicates that while relatively fewer issues were identified on paths, these user groups have a wide range of road-related issues. Interestingly, this exercise produced a greater array of issues than the prior accompanied journey surveys.

\section{Discussion}

As new public management, infrastructure and asset management principles have all co-evolved, synergies have emerged, particularly in the area of performance measurement and the establishment of service delivery indicators. Performance and organisational accountability has become inextricably linked with levels of service and technical outcomes in some areas, at least in the New Zealand land transport infrastructure sector (see Figure 10).

However, indicators are exactly that. At the strategic level, they can provide a health check on performance (Franco-Santos et al., 2007), and should not comprise the only organisational actions, but action is required if the indicators are to be used effectively (Kennerley and Neely, 2003). Each indicator may also have very different underlying objectives, and sometimes seek multiple, perhaps conflicting outcomes. The road smoothness indicator for comfort is one such example. It is a relatively simple measure that acts as an indicator for several outcomes, and in relation to a range of organisational accountabilities.

Exploring this performance measure has presented some interesting outcomes in its own right. However, it has also usefully enabled some of the complexities and interface between organisational and technical practice to be explored at a number of levels. The latter dimension will, however, be the subject of a separate paper. 


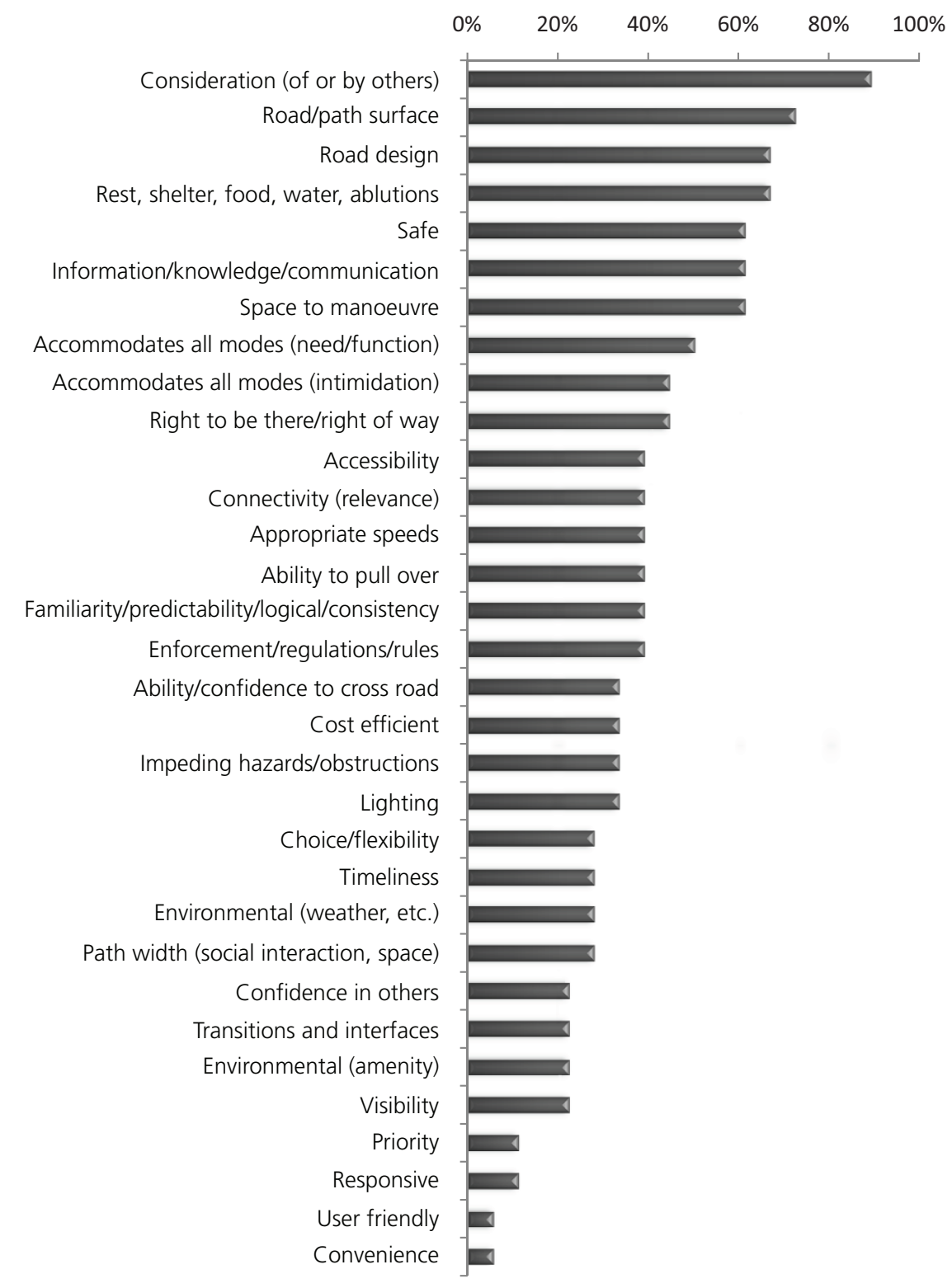

Figure 7. Frequency of comfort factors across all modes.

Percentage of the listed comfort factors that were identified as relevant to all modes (as listed in Figure 6)

The NZTA has adopted road smoothness as an indicator of customer comfort, technical conditions and road user costs. The use of measures such as the IRI, and its association with comfort, appears to be in line with general international practice. There are, however, few studies in this sector that take a step back and ask customers what comfort means to them more broadly, and whether smoothness is the best or sole indicator in this regard (the issue of perspective in public sector services was canvassed in the 1990s with regard to cultural safety and health care within New Zealand; see Koptie, 2009; Ramsden and Spoonley, 1993). Moreover, there does not appear to be any published or otherwise available work that directly compares changes in the smoothness indicator with changes in customer satisfaction (i.e. customer needs and outcomes).

Kennerley and Neely (2002) assert that performance measures should be dynamic and reviewed over time. In this vein it would be expected that customers would be asked periodically about comfort requirements as both society and technology changes over time (e.g. improved vehicle suspension may affect smoothness requirements (Brown et al., 2010); the emergence of motorised mobility scooters). It is cautioned against taking a conventional approach to such inquiry, however; asking customers directly about road smoothness is likely to restrict discussions to tensions or competing requirements 
Accommodation of all modes (needs/function)

Texture of roads and footpaths (good surface, debris, consistency, bumps)

Space to manoeuvre, others leave you space, width

Knowledge about where you can go/right of way, and information,

signage and directions, education

Tolerance/respect from others/of other users

Consistency of road and path design

Safe

Ability to cross roads (controlled crossings, priority)

Appropriate speeds

Enforcement, regulations, etc.

Connectedness of network

Accessibility

Accommodation of all modes (intimidation/feel unsafe)

Quick emergency response times

Being seen (road layout for visibility, driveways)

Feeling you belong

Ability to pull over (shoulders)

Stopping and rest areas

No obstacles (e.g. signs)

No congestion (timeliness, frustration)

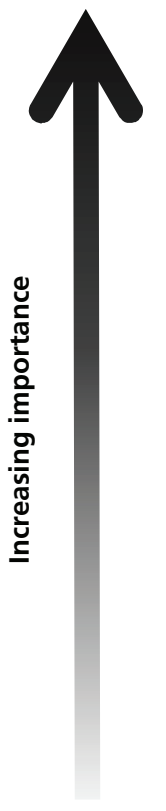

High importance

Table 3. Summary of customer comfort factors irrespective of mode

between user groups (e.g. cyclists might prefer smoother roads, but this might be dangerous for other user groups such as motorcyclists). This constraint was highlighted by this study, which inverted the conventional approach of starting with a given range of factors and in so doing gained a broad insight into customer needs. The customers themselves noted this and valued the ability to gain an understanding of other's needs. This approach also enabled these 'non-discursive' elements to be explored (Hillier, 2007). These are aspects 'we experience largely subconsciously and which we often do not have language to describe' (Penn in Knight and Ruddock, 2008).

The results show that while road smoothness is both a frequently identified and critical comfort factor, the notion of comfort is complex and cannot be considered in relation only to a single asset or mode if it is to have any real meaning to those the outcome is intended to benefit. Although the NZTA has a range of other performance indicators that might arguably address some of the wider comfort requirements, this case study has highlighted that there are limitations with taking these at face value or without considering the interplay between measures.

In the very least, feedback would suggest that any measure of smoothness needs to target

- the ride lines of the various users

- footpaths

- transitions between road and footpath and

- the road cross-section (inclusive of the road shoulder and transitions).
The case study also suggests that customer comfort is one particular result area that might lend itself to being refocused on vulnerable modes and users and broadened to accommodate the less tangible notions of comfort. Customer feedback suggests that increasing footpath width (to allow for socialising, reduce conflict, and provide for new modes) and improved cycle lanes (width and connectivity), for example, would contribute greatly to improved customer outcomes. This is, however, to be further explored through a national survey that will canvas wider customer views and will use the comfort factors defined by the preceding customer focus groups. How comfort might then be addressed by the organisation, inclusive of the less tangible or latent aspects, is then to be investigated as part of a further stage of the research.

All this is not to suggest that the IRI or road smoothness should be abandoned or is not an appropriate measure. Rather, there is an opportunity to consider whether there is a measure that is either 'mode agnostic' and/or better targets the vulnerable user, and in so doing provides more integrated and inclusive system level outcomes.

\section{Conclusions}

Approaching the strategic objective of delivering customer comfort through a different lens has served to highlight not only the inherent complexity of the notion of comfort itself but also the need to adopt a more holistic approach. The focus groups have highlighted the importance of effects on vulnerable users, reconciling user need, and in considering both footpaths and the road cross-section. While some might argue that this is not the primary focus of road, and less so 
Infrastructure Asset Management

Volume 2 Issue 1
Customer perceptions of road

infrastructure surface conditions

Blom, De Marco and Guthrie

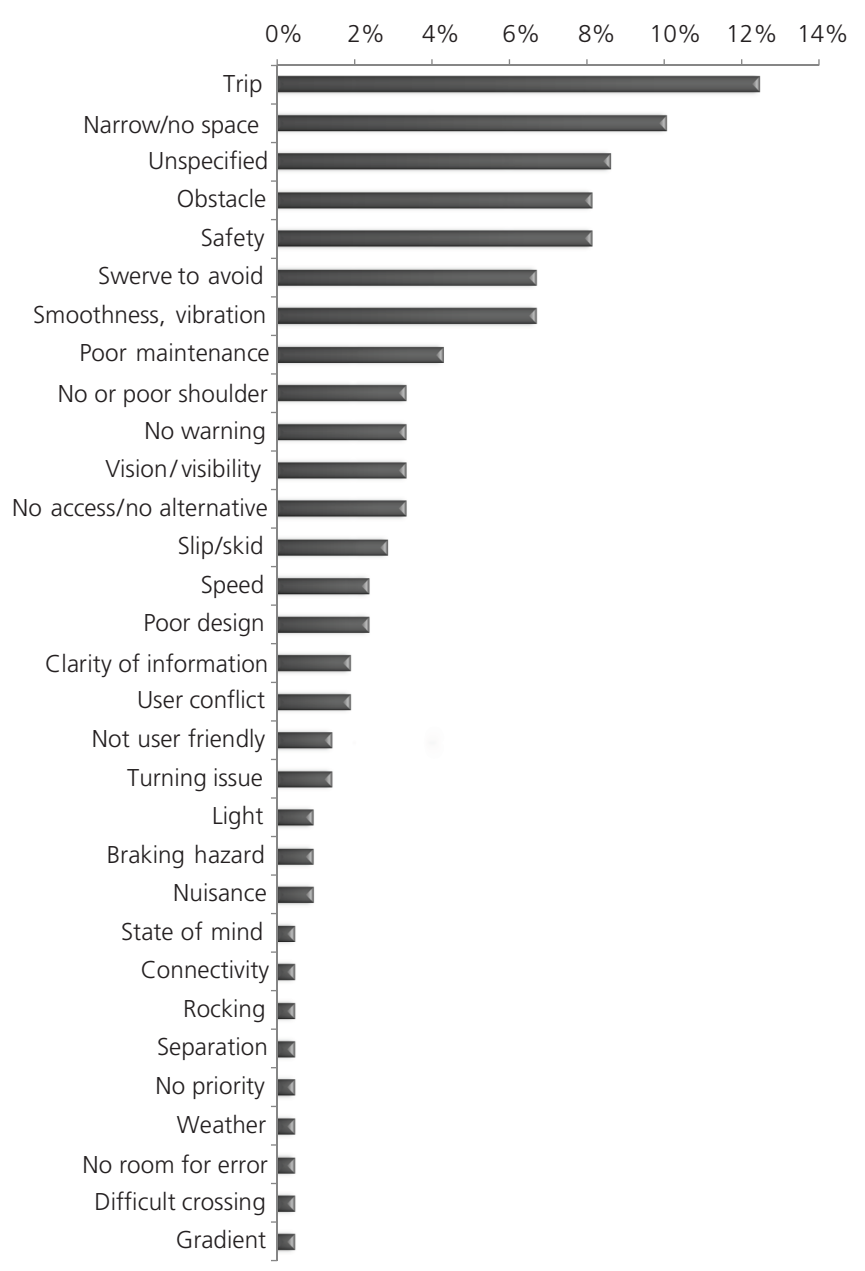

Figure 8. Overall keyword frequency of pavement issues

highway engineers (and there may be jurisdictional boundaries that reinforce this), it was the vulnerable user and non-vehicular modes that were of greatest importance to the actual customer despite the predominance of vehicular access and use among participants. Furthermore, technical, contract or jurisdictional boundaries appear to be of little relevance to the customer.

Although only in the initial stages, this research indicates the following

- The customers' concerns do not appear to match the current engineering or technical focus:

- The customers placed greater emphasis on a range of different factors and in relation to road smoothness were more concerned with the road cross-section.

- Paths and crossing transitions appear to play an important part in overall customer comfort. Pavement-related matters reinforced issues with trip hazards but also identified the importance of pavement width (the ability to socialise, navigate, share).

- Customers identified the need for designs to both evolve to accommodate new modes (e.g. mobility

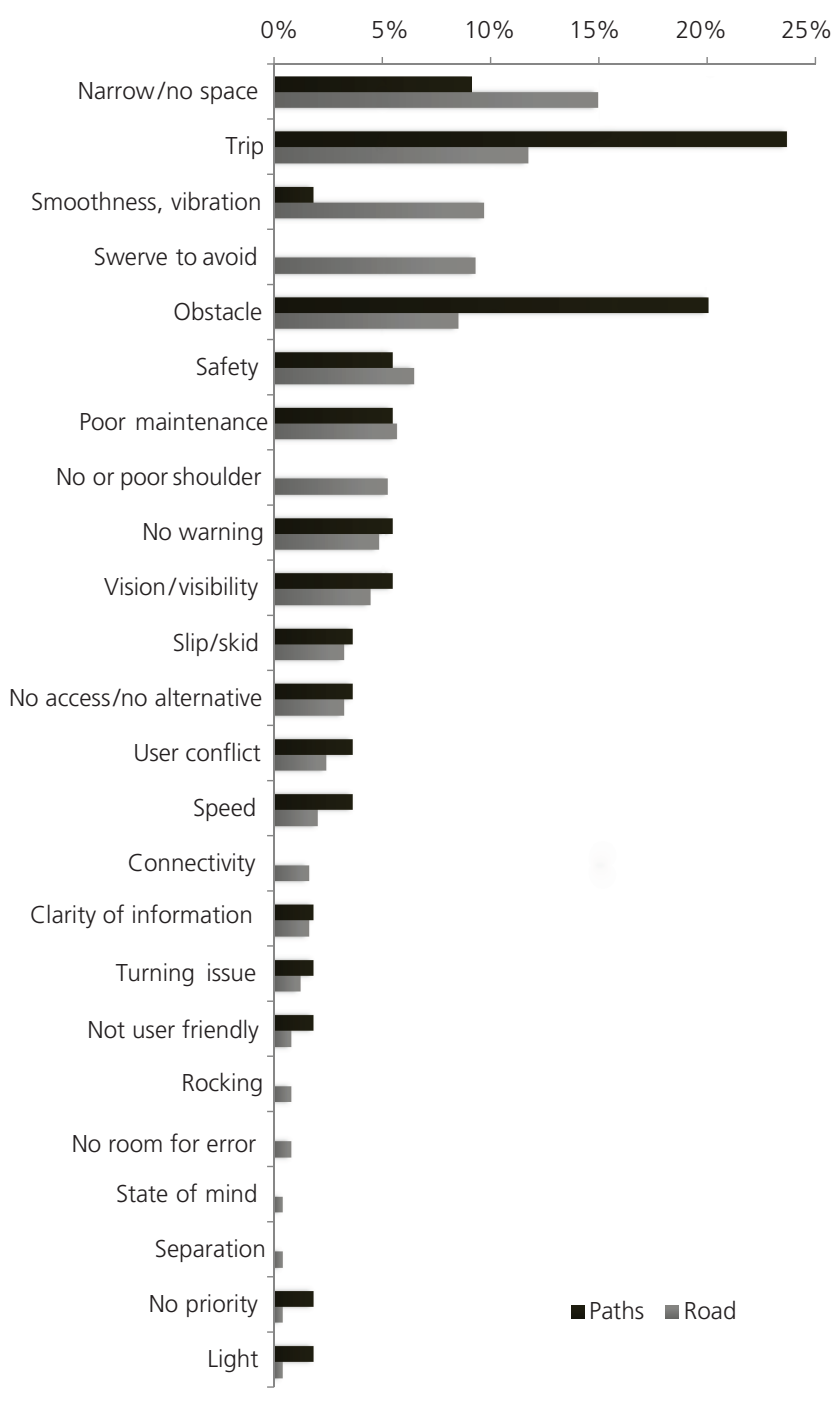

Figure 9. Keyword frequency for pavement issues for the top 50 ranking photographs

scooters), but not to the exclusion of others (e.g. the smoothing of radii, which makes cornering in a vehicle better but makes speeds difficult for pedestrians crossing the road).

- There was a feeling expressed that many of the effects on vulnerable groups were not as readily apparent (and without diminishing the impact) as say a death or serious injury on the road.

- Customers don't neatly aggregate or respond as modal groups. There are a range of user groups that give an added complexity across many modes, and customers view the issues across all their modal choices and experiences. This includes their interactions with other modes.

- There is a need to widen or change the lens being applied to performance indicators or other measures, to check that they are delivering the intended outcomes from the perspective of those they are intended to benefit. As indicators are never a complete measure, it is crucial then that these are supported, 


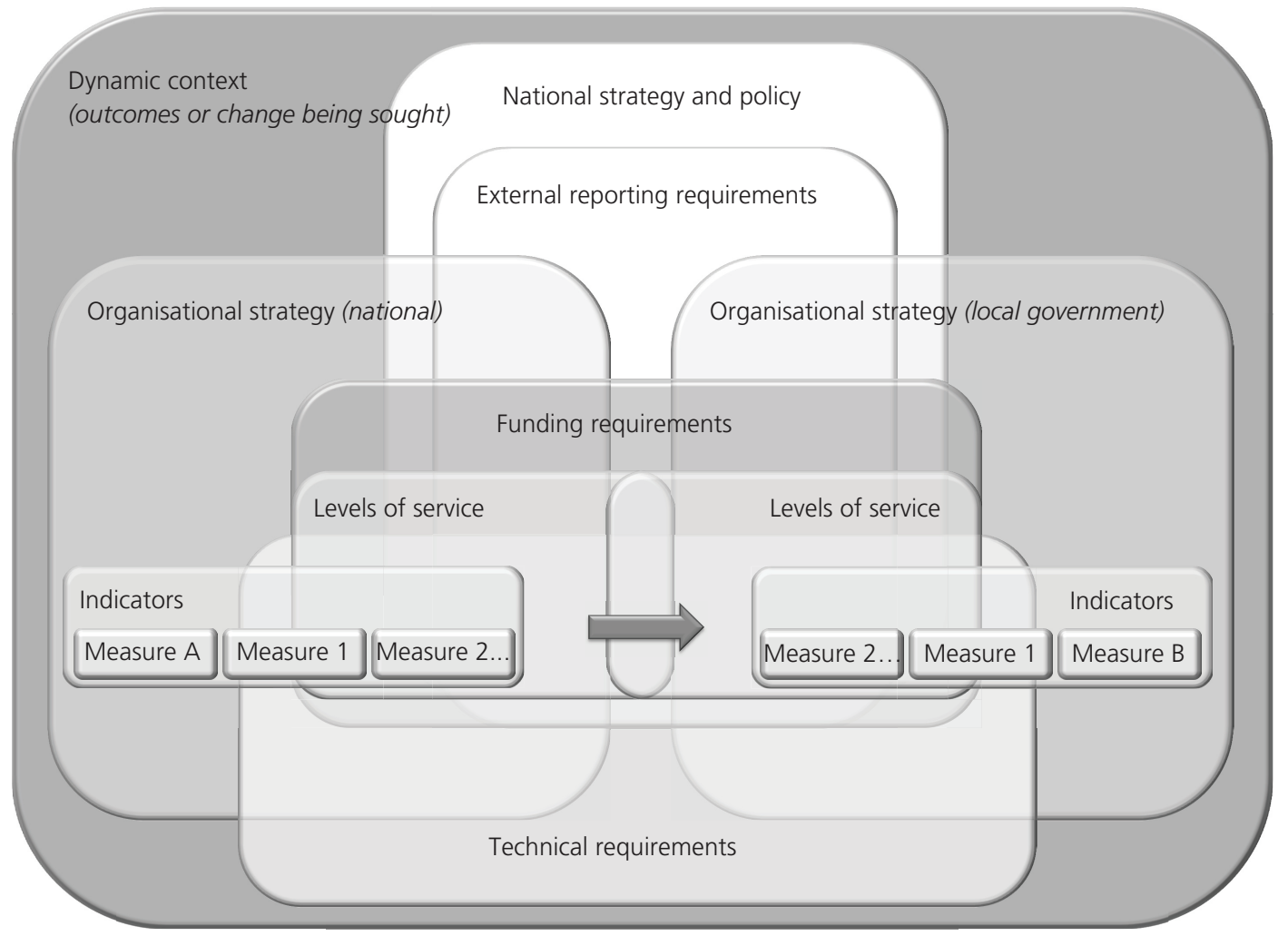

Figure 10. Overview of the New Zealand Land Transport Performance Measures Framework

augmented and reviewed so that the reason or outcome does not become secondary to the measure.

- If organisations, such as the NZTA, are to truly give effect to outwardly focused strategies, such as customer outcomes, then changes are likely to be needed to align current practice with strategic intent. This may include changes to technical specifications, contract boundaries and specifications (for example). This is likely to require further consideration of how conflicts between user groups and modes, as well as technical considerations, may be better reconciled.

- Any changes to orient technical practice with customer outcomes may also require interorganisational or industry alignment. For example, in New Zealand, NZTA practice has interfaces with local government, AustRoads, and central government reporting.

This exercise has provided a rich source of information and insight into customer needs, and how this interfaces with organisational drivers and technical performance. It has underscored the points that

- further research is required;

- the notion of comfort is indeed complex; and

- while performance indicators are a useful management tool, it is important not to wholly rationalise measures to fit technical requirements or preference.
If outcomes-based infrastructure management, and in particular customer-centric led strategies are to be adopted, then not only do these need to be supported through a more holistic philosophy, this may require a revision to how these are fundamentally approached in practice.

\section{Acknowledgements}

This research was funded by the NZTA. We are grateful to the community volunteers and agency staff that participated in this research, and who willingly and voluntarily gave their views and time. We also wish to thank Visiting Professor Charles Ainger (Centre for Sustainable Development, University of Cambridge) for his thoughtful review and encouragement.

\section{REFERENCES}

AustRoads (2011) User Satisfaction Index. See http://algin.net/ austroads/site/index.asp?id=93 (accessed 05/07/2014).

Bonsall P, Beale J, Paulley N and Pedler A (2005) The differing perspectives of road users and service providers. Transport Policy 12(4): 334-344.

Brebbia CA (2014) Urban Transport XX. WIT Press, Southampton, UK.

Brown D, Liu W and Henning T (2010) Identifying Pavement Deterioration by Enhancing the Definition of Road 
Roughness. NZTA Research Report 430. NZ Transport Agency, Wellington, New Zealand.

Department for Transport (UK) (2012) Prevention and a Better Cure: Potholes Review. Department for Transport, London, UK. Department of Internal Affairs (2013) Local Government NonFinancial Performance Measures. Department of Internal Affairs, Wellington, New Zealand.

Dobbs R, Pohl H, Lin DY et al. (2013) Infrastructure Productivity: How to Save \$1 Trillion a Year. McKinsey Global Institute, London, UK.

Dunleavy P and Hood C (1994) From old public administration to new public management. Public Money \& Management 14(3): 9-16.

Eboli L and Mazzulla G (2009) A new customer satisfaction index for evaluating transit service quality. Journal of Public Transportation 12(3): 21-37.

Eisenhardt K (1989) Building theories from case study research. Academy of Management Review 14(4): 532-550.

Franco-Santos M, Kennerley M, Micheli P et al. (2007) Towards a definition of a business performance measurement system. International Journal of Operations \& Production Management 27(8): 784-801.

Geiger D, Wells P, Bugas-Schramm P et al. (2005) Transportation Asset Management in Australia, Canada, England, and New Zealand. Report No. FHWA-PL-05-019. US Department of Transportation, Washington, DC, USA.

Government of Karnataka (2004) Second Road User Satisfaction Survey in Karnataka: Main Study Report (Final). Government of Karnataka, India. See http://www.kpwd.gov.in/pdf/ reports/RUSS\%20-II\%20FINAL\%20REPORT.pdf (accessed 31/03/2015).

Haas R, Felio G, Lounis Z and Cowe Falls L (2009) Measurable performance indicators for roads: Canadian and International Practice. Annual Conference of the Transportation Association of Canada, Vancouver, Canada. See http://conf.tac-atc.ca/ english/resourcecentre/readingroom/conference/conf2009/pdf/ Haas.pdf (accessed 31/03/2015).

Heath H and Cowley S (2004) Developing a grounded theory approach: a comparison of Glaser and Strauss. International Journal of Nursing Studies 41(2): 141-150.

Hendriks F and Tops P (1999) Between democracy and efficiency: trends in local government reform in the Netherlands and Germany. Public Administration 77(1): 133-153.

Hendriks F and Tops P (2003) Local public management reforms in The Netherlands: fads, fashions and winds of change. Public Administration 81(2): 301-323.

Henning T, Costello S and Tapper M (2013) Performance Indicator Analysis and Applying Levels of Service. Research Report 529. NZ Transport Agency, Wellington, New Zealand.

Hillier B (2007) Space is the Machine: A Configurational Theory of Architecture. Cambridge University Press, New York, USA.

Hood C (1991) A public management for all seasons? Public Administration 69(1): 3-19.

Johnson GC (undated) Impact of non-freeway rumble strips. Michigan Department of Transportation, Lansing, MI, USA.
See http://slidegur.com/doc/46033/impact-of-non-freewayrumble-strips (accessed 31/03/2015).

Jowitt P (2010) Now is the time. Proceedings of ICE-Civil Engineering 163(1): 3-8.

Kennerley M and Neely A (2002) A framework of the factors affecting the evolution of performance measurement systems. International Journal of Operations and Production Management 22(11): 1222-1245.

Kennerley M and Neely A (2003) Measuring performance in a changing business environment. International Journal of Operations \& Production Management 23(2): 213-229.

Key Research (2013) Gisborne District Council: Community Satisfaction Survey 2013 - Final Report. Gisborne District Council, Gisborne, New Zealand.

Knight A and Ruddock L (2008) Advanced Research Methods in the Built Environment. John Wiley \& Sons, Chichester, West Sussex, England.

Koptie S (2009) Irihapeti Ramsden: the public narrative on cultural safety. First Peoples Child \& Family Review 4(2): 30-43.

Krefting L (1991) Rigor in qualitative research: the assessment of trustworthiness. American Journal of Occupational Therapy 45(3): 214-222.

Kropáč O and Múčka P (2005) Be careful when using the International Roughness Index as an indicator of road unevenness. Journal of Sound and Vibration 287(4-5): 989-1003.

Lenngren C and Granlund J (2002) Relating road roughness to human discomfort and health impact. Proceedings of the 9 th International Conference on Asphalt Pavements. International Society for Asphalt Pavements, Copenhagen, Denmark.

Lowndes V (1997) Change in public service management: new institutions and new managerial regimes. Local Government Studies 23(2): 42-66.

Ministry of Transport (2013) Draft Government Policy Statment on Land Transport 2015. See http://www.transport.govt.nz/ ourwork/keystrategiesandplans/gpsonlandtransportfunding/ gps2015/.

Neely A and Bourne M (2000) Why measurement initiatives fail. Measuring Business Excellence 4(4): 3-7.

New Zealand Asset Management Support (NAMS) (2007) Developing Levels of Service and Performance Measures: Creating Customer Value from Community Assets. NAMS, Wellington, New Zealand.

New Zealand Government (2011) National Infrastructure Plan 2011. National Infrastructure Unit, NZ Government, Wellington, New Zealand. See http://www.infrastructure.govt. nz/plan/2011/nip-jul11.pdf (accessed 31/03/2015).

New Zealand Transport Agency (2000) SM020: State Highway Asset Management Manual. NZ Transport Agency, Wellington, New Zealand.

New Zealand Transport Agency (2009) Pavement Condition Surveys. NZ Transport Agency, Wellington, New Zealand. See http://www.nzta.govt.nz/network/maintaining/made-of/ pavement-condition.html (accessed 26/10/2014). 
New Zealand Transport Agency (2013) Procurement Manual (Chapter 11: Performance Measurement and Monitoring). NZ Transport Agency, Wellington, New Zealand.

New Zealand Transport Agency (2014) NZ Transport Agency Statement of Intent 2014-2018. See http://www.nzta.govt. nz/resources/statement-of-intent/docs/SOI-2014-18-web.pdf (accessed 31/03/2015).

Noxon Associates Limited (2011) Transportation Demand Management for Canadian Communities: A Guide to Understanding, Planning and Delivering TDM Programs. Transport Canada, Ottawa, Canada. See https://www.fcm.ca/ Documents/tools/GMF/Transport_Canada/TDMCanComm EN.pdf (accessed 31/03/2015).

Parasuraman A, Zeithaml VA and Berry LL (1985) A conceptual model of service quality and its implications for future research. Journal of Marketing 49(4): 41-50.

Parasuraman A, Zeithaml VA and Berry LL (1994) Reassessment of expectations as a comparison standard in measuring service quality: implications for further research. Journal of Marketing 58(1): 111-124.

Ramdas V, Thomas C, Lehman C and Young D (2007) Highway Service Levels. Report number: PPR 251. TRL and Ipsos MORI, London, UK.
Ramsden I and Spoonley P (1993) The cultural safety debate in nursing education in Aotearoa. New Zealand Annual Review of Education 3: 161-174.

Solhmirzaei A, Azadi S and Kazemi R (2012) Road profile estimation using wavelet neural network and 7-DOF vehicle dynamic systems. Journal of Mechanical Science and Technology 26(10): 3029-3036.

Stokols D (2006) Toward a science of transdisciplinary action research. American Journal of Community Psychology 38(1-2): 63-77.

Transfund New Zealand (1997) RAMM - Road Condition Rating and Roughness Manual. See http://www.nzta.govt.nz/ resources/road-assessment-and-maintenance-management/ (accessed 19/03/2015).

Versus Research (2013) Annual Customer Views Survey Report: Matamata-Piako District Council. Matamata Piako District Council, Matamata, New Zealand. See http://www.mpdc.govt. nz/pdf/Reports/2013AnnualCustomerSurvey.pdf (accessed 31/03/2015).

Wilson D, Jacobsen B and Chan W (2013) The Effect of Road Roughness (and Test Speed) on Griptester Measurements. Research Report 523. NZ Transport Agency, Wellington, New Zealand.

\section{WHAT DO YOU THINK?}

To discuss this paper, please submit up to 500 words to the editor at journals@ice.org.uk. Your contribution will be forwarded to the author(s) for a reply and, if considered appropriate by the editorial panel, will be published as a discussion in a future issue of the journal. 